\title{
SISTEM PENDUKUNG KEPUTUSAN PENILAIAN KINERJA DOSEN DENGAN MENGGUNAKAN METODE MULTI ATTRIBUTE UTILITY THEORY ( MAUT )
}

\author{
Dasril Aldo ${ }^{1)}$, Nursaka Putra' ${ }^{2)}$, Zainul Munir ${ }^{3)}$ \\ ${ }^{1)}$ Program Studi Sistem Informasi, STMIK GICI, Batam \\ ${ }^{2)}$ Program Studi Manajemen Informatika, Universitas CIC, Cirebon \\ ${ }^{3)}$ Program Studi Manajemen Informatika, STMIK GICI, Batam
}

email: dasrilaldo1994@gmail.com,nursaka.putra@cic.ac.id, bapakmunir@gmail.com

\begin{abstract}
Abstrak
SPK merupakan sistem informasi yang dibangun dalam bentuk interaktif untuk menyediakan informasi, pemodelan, dan pemanipulasian data dalam menghasilkan keputusan. Metode MAUT digunakan sebagai peubah dari beberapa kepentingan dalam bentuk nilai numerik yang skala 0-1 nilai 0 mewakili nilai buruk sedangkan 1 nilai terbaik. Dosen merupakan pendidik profesional dan ilmuwan yang mempunyai tugas utama untuk mengembangkan, mentransformasika, dan menyebarluaskan berbagai ilmu pengetahuan melalui pendidikan, penelitian, dan pengabdian kepada masyarakat. Proses evaluasi kinerja dosen adalah kegiatan yang harus dilaakukan secara rutin dilaksanakan pada perguruan tinggi dalam meningkatkan kualitas dosen secara berkelanjutan. Adapun kriteria yang digunakan dalam SPK ini adalah Penguasaan dan Kemampuan dalam menjelaskan, Kemampuan dalam menjawab pertanyaan, Kemampuan dalam memberi motivasi mahasiswa, Kemampuan membuat suasana kelas menyenangkan, Kedisiplinan hadir dalam perkuliahan. Hasil dari penelitian ini berupa bobot yang dapat menentukan apakah kinerja dari dosen yang dinilai bagus atau tidak.
\end{abstract}

\section{Kata Kunci: SPK, Attribute Utility Theory ( MAUT ), Kinerja Dosen}

\begin{abstract}
DSS is an information system that was built in an interactive form to provide information, modeling, and manipulation of data in generating decisions. The MAUT method is used as a variable of some importance in the form of numerical values where the scale of 0-1 values 0 represents a bad value while 1 is the best value. Lecturers are professional educators and scientists whose main task is to develop, transform, and disseminate various sciences through education, research, and community service. The process of evaluating lecturer performance is an activity that must be carried out routinely carried out at universities in order to continuously improve the quality of lecturers. The criteria used in this SPK are Mastery and Ability to explain, Ability to answer questions, Ability to motivate students, Ability to create a pleasant classroom atmosphere, Discipline is present in lectures. The results of this study in the form of weight scores that can determine whether the performance of lecturers who are considered good or not
\end{abstract}

Keywords: DSS, Attribute Utility Theory (MAUT), Lecturer Performance

\section{PENDAHULUAN}

Seiring dengan pengembangan teknologi dimasa sekarang, penggunaan teknologi informasi dapat dijadikan suatu media yang dapat membantu pekerjaan manusia. Dengan kemudahan pengaksesan dan interface yang user friendly dapat menimbulkan kenyamanan yang berbeda dibanding cara tradisional yang membutuhkan kertas untuk mengolah data. Kondisi tersebut merupakan kesempatan 
dalam memanfaatkan perkenbangan teknologi dalam implementasi pengolahan data penilaian kinerja dosen lebih efisien.

Penelitian terdahulu yang pernah melakukan penelitian tentang kinerja dosen diantaranya adalah Kholdani, dkk (2017), dimana hasil penelitiannya adalah "berhasil melakukan perangkingan alternatif dari hasil perhitungan pembobotan nilai kinerja dosen Fakultas Teknologi Informasi Universitas MAB Banjarmasin. Perhitungan dari kriteria mahasiswa, rekan sejawat, pimpinan dan dosen sebagai diri sendiri menggunakan metode Simple Additive Weighting (SAW)memberikan hasil yang adil dan objektif terhadap kinerja dosen. kemudian hasil Simple Additive Weighting (SAW) yang diperoleh tadi, menjadi kriteria baru yang digabung dengan perhitungan pada internal akademik yaitu kriteria penelitian, pengabdian, pengajaran dan pembimbingan menggunakan metode Analytical Hierarchy Process (AHP) dan hasilnya merupakan keputusan akhir" [1].

Peningkatan kualitas Sumber Daya Manusia (SDM) merupakan hal yang harus secara terus menerus dilakukan. Terutama bagi tenaga dosen yang berkualitas dan memiliki kinerja yang baik. Sekolah Tinggi Manajemen Informatika dan Komputer (STMIK) GICI Batam merupakan salah satu perguruan tinggi yang dikelola Yayasan Permata Harapan Bangsa Batam, dimaksudkan untuk menghasilkan lulusan yang mampu berkontribusi dalam penyiapan SDM terampil dan berdaya saing global. Untuk memwujudkan lulusan tersebut maka tenaga pengajar atau dosen dituntut untuk memiliki kualitas dan kinerja yang baik.

Alasan penulis melakukan penelitian ini adalah belum ada nya sistem yang digunakan di STMIK GICI dalam mengolah data penilaian kinerja dosen.

Masalah yang ditangani pada penelitian ini adalah pembuatan sistem yang dapat digunakan untuk penilaian kinerja dosen sehingga dosen yang memiliki kinerja baik dapat meningkatkan kinerjanya, sedangkan dosen yang memiliki kinerja tidak baik dapat memperbaiki kinerjanya.

Penulis menggunakan metode Attribute Utility Theory (MAUT), Adapun tema atau judul yang akan dibahas adalah " Sistem Pendukung Keputusan Penilaian Kinerja Dosen Dari Dengan menerapkan Metode Attribute Utility Theory (MAUT)".

\section{LANDASAN TEORI}

\section{Sistem Pendukung Keputusan}

Sistem Pendukung Keputusan adalah sistem yang berbasis komputer yang dapat membantu pengambilan keputusan untuk memecahkan masalah tertentu dengan memanfaatkan data dan model tertentu. Turban (1990) dan Turban \& Aronson (2001) menyebutkan bahwa konsep sistem penunjang kaputusan (SPK) muncul pertama kali pada tahun 1970-an oleh Scott-Morton. Mereka mendefenisikan sistem sebagai suatu sistem interaktif berbasis komputer yang dapat membantu para pengambil keputusan dalam menggunakan data dan model untuk memecahkan masalah yang bersifat tdak terstruktur [2].

Pada dasarnya SPK merupakan pengembangan lebih lanjut dari Sistem Informasi Manajemen terkomputerisasi yang dirancang sedemikian rupa sehingga bersifat interaktif dengan pemakainya. Interaktif dengan tujuan untuk memudahkan integrasi antara berbagai komponen dalam proses pengambilan keputusan seperti prosedur, kebijakan, analisis, pengalaman dan wawasan manajer 
untuk mengambil keputusan yang lebih baik [3].

\section{Metode MAUT}

Metode Multi-Attribute Utility Theory (MAUT) merupakan suatu metode perbandingan kuantitatif yang biasanya mengkombinasikan pengukuran atas biaya resiko dan keuntungan yang berbeda. Setiap kriteria yang ada memiliki beberapa alternatif yang mampu memberikan solusi. Untuk mencari alternatif yang mendekati dengan keinginan user maka untuk mengidentifikasikannya dilakukan perkalian terhadap skala prioritas yang sudah ditentukan. Sehingga hasil yang terbaik dan paling mendekati dari alternatif-alternatif tersebut yang akan diambil sebagai solusi [4].

MAUT digunakan untuk merubah dari beberapa kepentingan kedalam nilai numerik dengan skala 0-1 dengan 0 mewakili pilihan terburuk dan 1 terbaik. Hal ini memungkinkan perbandingan langsung yang beragam ukuran [5].

\section{Dosen}

Dosen adalah salah satu unsur penting dalam pembangunan nasional karena dosen adalah agen perubahan di bidang pendidikan. Menurut Undang Undang Republik Indonesia nomor 14 tahun 2005 tentang guru dan dosen, dosen adalah pendidik profesional dan ilmuwan dengan tugas utama mentransformasikan, mengembangkan, dan menyebarluaskan ilmu pengetahuan, teknologi, dan seni melalui pendidikan, penelitian, dan pengabdian kepada masyarakat [6].

\section{METODE PENELITIAN}

Kerangka penelitian adalah urutan yang akan dilakukan dalam suatu penelitian. Agar langkah-langkah yang diambil penulis dalam perancangan ini tidak melenceng dari pokok pembicaraan dan lebih mudah dipahami, maka urutan langkah-langkah penelitian akan dibuat secara sistematis dan dapat digunakan sebagai pedoman yang jelas serta mudah untuk menyelesaikan permasalahan yang ada. Urutan langkah-langkah yang akan dibuat pada penelitian ini dapat dilihat pada gambar berikut ini :

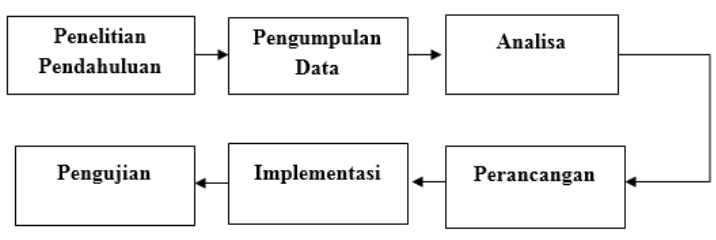

\section{Gambar 1. Metodologi Penelitian}

\section{HASIL DAN PEMBAHASAN}

\section{Analisa Data}

Proses analisa data yaitu merupakan salah satu tahapan yang penting dalam penelitian ini, karena pada tahap inilah nantinya dilakukan dentifikasi terhadap masalah yang ada dalam penilaian kinerja dosen di STMIK GICI.

Analisa masalah dilakukan agar penemuan-penemuan masalah yang didapat dapat diketahui penyebabnya, sehingga dari analisa masalah tersebut didapatkan suatu bentuk pemecahan masalah.

Pemecahan masalah adalah suatu cara yang dapat menyelesaikan masalah yang telah dijelaskan pada analisa masalah di atas adalah dengan membangun sistem pendukung keputusan dalam penilaian kinerja dosen.

\section{Analisa Proses Dengan MAUT}

Multi Atribute Utility Theory

(MAUT) merupakan suatu skema yang evaluasi akhir, $\mathrm{v}(\mathrm{x})$ dari suatu objek $\mathrm{x}$ 
didefinisikan sebagai bobot yang dijumlahkan dengan suatu nilai yang relevan terhadap nilai dimensinya. Ungkapan yang biasa digunakan untuk menyebutnya adalah nilai utilitas. MAUT digunakan untuk merubah dari beberapa kepentingan kedalam nilai numerik dengan skala -1 dengan 0 mewakili pilihan terburuk dan 1 terbaik. Hal ini dapat menjadikan perbandingan secara langsung yang beragam ukuran. Hasil akhirnya dari penelitian yang dilakukan adalah berupa urutan dari peringkat evaluasi yang dapat menggambarkan pilihan dari para pembuat keputusan.

1. Menentukan kriteria-kriteria yang akan dijadikan acuan dalam pengambilan keputusan, yaitu $\mathrm{Ki}$. Dimana kriteria yang digunakan dalam SPK ini adalah sebagai berikut:
a. $\mathrm{K} 1=$ Penguasaan dan Kemampuan dalam menjelaskan
b. $\mathrm{K} 2=$ Kemampuan dalam menjawab pertanyaan
c. $\mathrm{K} 3=$ Kemampuan dalam memberi motivasi mahasiswa
d. $\mathrm{K} 4=$ Kemampuan membuat suasana kelas menyenangkan
e. $\mathrm{K} 5=$ Kedisiplinan hadir dalam perkuliahan

Selanjutnya akan dilakukan penentuan bobot setiap nilai yang terdapat pada siswa seperti berikut:

Tabel 1 Bobot Kriteria

\begin{tabular}{|c|c|}
\hline Kode & Bobot \\
\hline K1 & 0,30 \\
\hline K2 & 0,15 \\
\hline K3 & 0,15 \\
\hline K4 & 0,20 \\
\hline K5 & 0,20 \\
\hline
\end{tabular}

Selanjutnya akan digunakan nilai berdasarkan indikator peberikut:

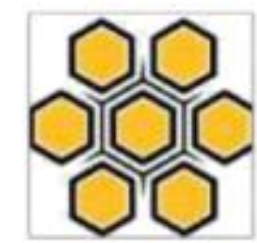

\begin{tabular}{|c|c|}
\multicolumn{2}{c}{ Tabel 2 Indikator Penilaian } \\
\hline Indikator & Nilai \\
\hline Sangat Baik & 5 \\
\hline Baik & 4 \\
\hline Cukup & 3 \\
\hline Buruk & 2 \\
\hline Sangat Buruk & 1 \\
\hline
\end{tabular}

Setelah nilai indikator diketahui, selanjutnya akan digunakan data penilaian yang didapatkan seperti tabel berikut:

Tabel 3 Data Nilai Dosen

\begin{tabular}{|c|c|c|c|c|c|c|}
\hline NO & Dosen & K1 & K2 & K3 & K4 & K5 \\
\hline 1 & $\begin{array}{c}\text { DSN- } \\
01\end{array}$ & $\mathbf{4}$ & $\mathbf{5}$ & $\mathbf{5}$ & $\mathbf{5}$ & $\mathbf{4}$ \\
\hline 2 & $\begin{array}{c}\text { DSN- } \\
02\end{array}$ & $\mathbf{4}$ & $\mathbf{5}$ & $\mathbf{5}$ & $\mathbf{5}$ & $\mathbf{4}$ \\
\hline 3 & $\begin{array}{c}\text { DSN- } \\
03\end{array}$ & $\mathbf{3}$ & $\mathbf{5}$ & $\mathbf{3}$ & $\mathbf{4}$ & $\mathbf{5}$ \\
\hline 4 & $\begin{array}{c}\text { DSN- } \\
04\end{array}$ & $\mathbf{3}$ & $\mathbf{4}$ & $\mathbf{5}$ & $\mathbf{5}$ & $\mathbf{5}$ \\
\hline 5 & $\begin{array}{c}\text { DSN- } \\
05\end{array}$ & $\mathbf{4}$ & $\mathbf{3}$ & $\mathbf{2}$ & $\mathbf{5}$ & $\mathbf{4}$ \\
\hline 6 & $\begin{array}{c}\text { DSN- } \\
06\end{array}$ & $\mathbf{4}$ & $\mathbf{5}$ & $\mathbf{4}$ & $\mathbf{2}$ & $\mathbf{3}$ \\
\hline
\end{tabular}

Normalisasi matrik ditentukan dengan rumus:

$$
U_{(x)}=\frac{X-X_{i}^{-}}{X_{i}^{+}-X_{i}^{-}}
$$

$\mathrm{X}=$ Bobot alternatif

$X_{i}^{-}=$Bobot terburuk (minimum) dari kriteria ke-X

$X_{i}^{+}=$Bobot terbaik (maximum) dari kriteria ke-X

Berikut perhitungan matrik normalisasi :

a. Normalisasi DSN-01 (A1)

$$
\begin{aligned}
& A 1_{1}=\frac{4-3}{4-3}=\frac{1}{1}=1 \\
& A 1_{2}=\frac{5-3}{5-3}=\frac{2}{2}=1 \\
& A 1_{3}=\frac{5-2}{5-2}=\frac{3}{3}=1 \\
& A 1_{4}=\frac{5-2}{5-2}=\frac{3}{3}=1
\end{aligned}
$$




$$
A 1_{5}=\frac{4-3}{5-3}=\frac{1}{2}=0,5
$$

b. Normalisasi DSN-02 (A2)

$$
\begin{aligned}
& A 2_{1}=\frac{4-3}{4-3}=\frac{1}{1}=1 \\
& A 2_{2}=\frac{5-3}{5-3}=\frac{2}{2}=1 \\
& A 2_{3}=\frac{5-2}{5-2}=\frac{3}{3}=1 \\
& A 2_{4}=\frac{5-2}{5-2}=\frac{3}{3}=1 \\
& A 2_{5}=\frac{4-3}{5-3}=\frac{1}{2}=0,5
\end{aligned}
$$

c. Normalisasi DSN-03 (A3)

$$
\begin{aligned}
& A 3_{1}=\frac{3-3}{4-3}=\frac{0}{1}=0 \\
& A 3_{2}=\frac{5-3}{5-3}=\frac{2}{2}=1 \\
& A 3_{3}=\frac{3-2}{5-2}=\frac{1}{3}=0,33 \\
& A 3_{4}=\frac{4-2}{5-2}=\frac{2}{3}=0,67 \\
& A 3_{5}=\frac{5-3}{5-3}=\frac{2}{2}=1
\end{aligned}
$$

d. Normalisasi DSN-04 (A4)

$$
\begin{aligned}
& A 4_{1}=\frac{3-3}{4-3}=\frac{0}{1}=0 \\
& A 4_{2}=\frac{4-3}{5-3}=\frac{1}{2}=0,5 \\
& A 4_{3}=\frac{5-2}{5-2}=\frac{3}{3}=1 \\
& A 4_{4}=\frac{5-2}{5-2}=\frac{3}{3}=1 \\
& A 4_{5}=\frac{5-3}{5-3}=\frac{2}{2}=1
\end{aligned}
$$

e. Normalisasi DSN-05 (A6)

$$
\begin{aligned}
& A 5_{1}=\frac{4-3}{4-3}=\frac{1}{1}=1 \\
& A 5_{2}=\frac{3-3}{5-3}=\frac{0}{2}=0 \\
& A 5_{3}=\frac{2-2}{5-2}=\frac{0}{3}=0
\end{aligned}
$$

$$
\begin{aligned}
& A 5_{4}=\frac{5-2}{5-2}=\frac{3}{3}=1 \\
& A 5_{5}=\frac{4-3}{5-3}=\frac{1}{2}=0,5
\end{aligned}
$$

f. Normalisasi DSN-06 (A6)

$$
\begin{aligned}
& A 6_{1}=\frac{4-3}{4-3}=\frac{1}{1}=1 \\
& A 6_{2}=\frac{5-3}{5-3}=\frac{2}{2}=1 \\
& A 6_{3}=\frac{4-2}{5-2}=\frac{2}{3}=0,67 \\
& A 6_{4}=\frac{2-2}{5-2}=\frac{0}{3}=0 \\
& A 6_{5}=\frac{3-3}{5-3}=\frac{0}{2}=0
\end{aligned}
$$

Dari hasil normalisasi tersebut, akna di tampilkan dalam bentuk tabel seperti berikut:

\section{Tabel 4 Normalisasi Matrik MAUT}

\begin{tabular}{|l|l|c|c|c|c|c|}
\hline No & Nama & C1 & C2 & C3 & C4 & C5 \\
\hline 1 & $\begin{array}{l}\text { DSN- } \\
01\end{array}$ & 1 & 1 & 1 & 1 & 0,5 \\
\hline 2 & $\begin{array}{l}\text { DSN- } \\
02\end{array}$ & 1 & 1 & 1 & 1 & 0,5 \\
\hline 3 & $\begin{array}{l}\text { DSN- } \\
03\end{array}$ & 0 & 1 & 1 & 1 & 1 \\
\hline 4 & $\begin{array}{l}\text { DSN- } \\
04\end{array}$ & 0 & 0,5 & 1 & 1 & 1 \\
\hline 5 & $\begin{array}{l}\text { DSN- } \\
05\end{array}$ & 1 & 0 & 0 & 1 & 0,5 \\
\hline 6 & $\begin{array}{l}\text { DSN- } \\
06\end{array}$ & 1 & 1 & 0,67 & 0 & 0 \\
\hline
\end{tabular}

Tahap selanjutnya akan dilakukan perkalian matrik normalisasi dengan bobot preferensi dengan menggunakan rumus:

$V_{(x)}=\sum_{i=1}^{n} W j . X i j$

Berikut perhitungan perkalian matrik normalisai dengan menggunakan persamaan (1):

$$
\begin{aligned}
\mathrm{A} 1= & (0,30 * 1)+(0,15 * 1)+(0,15 * 1)+ \\
& (0,20 * 1)+(0,20 * 0,5)
\end{aligned}
$$




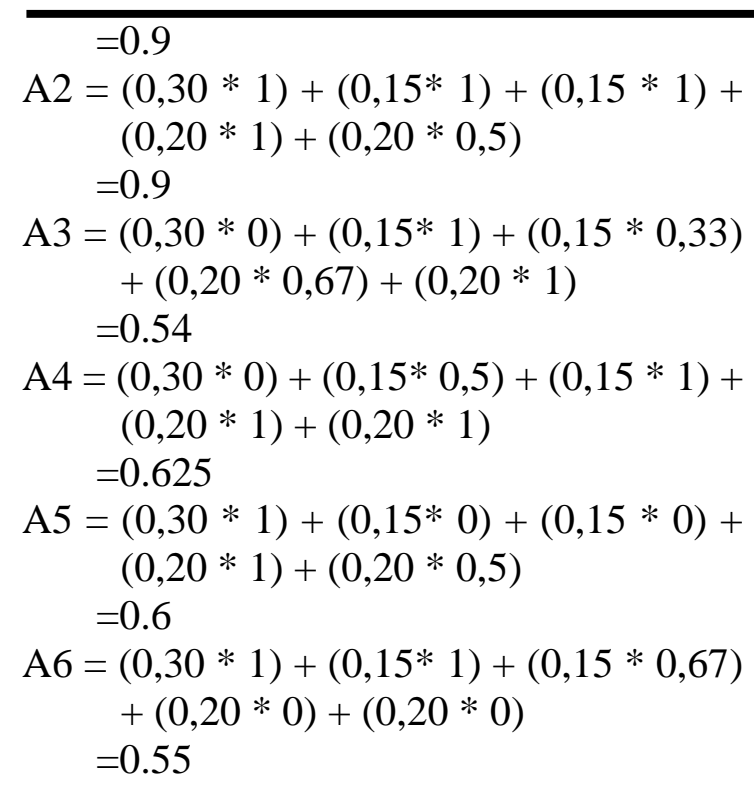

Dari hasil persamaan maka akan dihasilkan perkalian matrik normalisasi yang ditampilkan pada tabel berikut:

Tabel 5 Hasil Akhir

\begin{tabular}{|c|c|c|}
\hline No & Nama & No \\
\hline 1 & DSN-01 & 0,9 \\
\hline 2 & DSN-02 & 0,9 \\
\hline 3 & DSN-03 & 0,54 \\
\hline 4 & DSN-04 & 0,625 \\
\hline 5 & DSN-05 & 0,6 \\
\hline 6 & DSN-06 & 0,55 \\
\hline
\end{tabular}

\section{HASIL}

Hasil dari penelitian ini berupa keputusan dosen yang memiliki kinerja baik dan dosen memiliki kinerja buruk, dimana nilai $\geq 0,60$ memiliki predikat kinerja baik dan $<60$ memiliki kinerja buruk. Dari hasil perhitungan metode MAUT didapatkan hasil keputusan sebagai berikut:

Tabel 6 Keputusan

\begin{tabular}{|c|c|c|c|}
\hline No & Nama & No & Keputusan \\
\hline 1 & DSN-01 & 0,9 & Kinerja Baik \\
\hline 2 & DSN-02 & 0,9 & Kinerja Baik \\
\hline 3 & DSN-03 & 0,54 & Kinerja Buruk \\
\hline 4 & DSN-04 & 0,625 & Kinerja Baik \\
\hline 5 & DSN-05 & 0,6 & Kinerja Baik \\
\hline
\end{tabular}

\section{\begin{tabular}{|l|l|l|l|}
\hline 6 & DSN-06 & 0,55 & Kinerja Buruk \\
\hline
\end{tabular}}

\section{SIMPULAN}

Dari uraian masalah di atas, serta berdasarkan analisa dari bab-bab yang ada, maka dapat ditarik kesimpulan sebagai berikut:

1. Metode MAUT mampu melakukan pengolahan data dosen dengan menghasilkan keputusan berupa dosen yang memiliki kinerja Baik dan Buruk.

2. Hasil penelitian ini dapat memberikan informasi mengenai data nilai kinerja dosen.

3. Hasil penelitian ini menunjukan terdapat 4 (empat) dosen memiliki kinerja baik dan 2 (dua) dosen memiliki kinerja buruk.

\section{DAFTAR PUSTAKA}

Muflih, M., \& Arminarahmah, N. (2017). Sistem Pendukung Keputusan Penilaian Kinerja Dosen Dengan Metode Ahp Dan Saw. Jurnal Teknologi Informasi Universitas Lambung Mangkurat (JTIULM), 2(1), 15-21.

Aldo, D. (2019). Pemilihan Bibit Lele Unggul dengan Menggunakan Metode Weighted Product. Jurnal Teknologi dan Open Source, 2(1), 15-23.

Basri, B. (2017). Metode Weightd Product (Wp) Dalam Sistem Pendukung Keputusan Penerimaan Beasiswa Prestasi. Jurnal Insypro (Information System And Processing), 2(1).

Israwan, L. F., Mukmin, M., \& Ardiansyah, S. (2018). Penentuan Karyawan Berprestasi Menggunakan Metode Multi Attribute Utility Theory (MAUT). Jurnal Informatika, 9(1). 
Hadinata, N. (2018). Implementasi Metode Multi Attribute Utility Theory (MAUT) Pada Sistem Pendukung Keputusan dalam Menentukan Penerima Kredit. Jurnal Sisfokom (Sistem Informasi dan Komputer), 7(2), 87-92.

Piscayanti, K. S. (2015). Pengaruh Sertifikasi Dosen Terhadap Kinerja Pengajaran Dosen Undiksha. Jurnal Ilmu Sosial dan Humaniora, 4(1). 